\title{
STRONG APPROXIMATION OF ALMOST PERIODIC FUNCTIONS
}

\section{WŁODZIMIERZ ŁENSKI AND BOGDAN SZAL}

Abstract. We consider summability methods generated by the class $G M\left({ }_{2} \beta\right)$. We generalize some related results of P. Pych-Taberska [Studia Math. XCVI (1990), 91-103] on strong approximation of almost periodic functions by their Fourier series and S. M. Mazhar and V.Totik [J. Approx. Theory, 60(1990), 174-182] on approximation of periodic functions by matrix means of their Fourier series.

Mathematics subject classification (2010): 42A24.

Keywords and phrases: Almost periodic functions, rate of strong approximation, summability of Fourier series.

\section{REFERENCES}

[1] A. Avantaggiati, G. BRuno and B. Iannacci, The Hausdorff-Young theorem for almost periodic functions and some applications, Nonlinear analysis, Theory, Methods and Applications, Vol. 25, No. 1, (1995), pp. 61-87.

[2] A. D. BAiley, Almost Everywhere Convergence of Dyadic Partial Sums of Fourier Series for Almost Periodic Functions, Master of Philosophy, A thesis submitted to School of Mathematics of The University of Birmingham for the degree of Master of Philosophy, September 2008.

[3] A. S. Besicovitch, Almost periodic functions, Cambridge, 1932.

[4] E. A. BREDIKHINA, On the best approximation of almost periodic functions by entire functions of finite order, Dokl. Akad. Nauk SSSR 117 (1957), 17-20 (in Russian).

[5] L. LEINDLER, On the uniform convergence and boundedness of a certain class of sine series, Analysis Math., 27 (2001), 279-285.

[6] L. LeIndLER, Integrability conditions pertaining to Orlicz space, J. Inequal. Pure and Appl. Math., 8 (2) (2007), Art. 38, 6 pp.

[7] L. LeIndLER, A new extension of monotone sequence and its application, J. Inequal. Pure and Appl. Math., 7 (1) (2006), Art. 39, 7 pp.

[8] L. LEINDLER, Strong approximation by Fourier series, Akadémiai Kiadó (Budapest, 1985).

[9] B. L. Levitan, Almost periodic functions, Gos. Izdat. Tekh-Teoret. Liter., Moscov 1953 (in Russian).

[10] S. M. MaZhar AND V. TotiK, Approximation of continuous functions by $T$-means of Fourier series, J. Approx. Theory, 60 (1990), 174-182.

[11] P. PYCH-TABERSKA, Approximation properties of the partial sums of Fourier series of almost periodic functions, Studia Math. XCVI (1990), 91-103.

[12] B. SZAL, On the degree of strong approximation of continuos functions by special matrix, J. Inequal. Pure and Appl. Math., 10, 4 (2009), Art. 111, 8 pp.

[13] B. SzAL, A note on the uniform convergence and boundedness a generalized class of sine series, Commentat. Math., 48, 1 (2008), 85-94.

[14] S. TikHonov, Trigonometric series with general monotone coefficients, J. Math. Anal. Appl., 326 (1) (2007), 721-735.

[15] S. Tikhonov, On uniform convergence of trigonometric series, Mat. Zametki, 81 (2) (2007), 304310, translation in Math. Notes, 81 (2) (2007), 268-274.

[16] S. TikHonov, Best approximation and moduli of smoothness: Computation and equivalence theorems, J. Approx. Theory, 153 (2008), 19-39.

[17] A. Zygmund, Trigonometric series, Cambridge, 2002. 